\title{
PERBEDAAN HASIL BELAJAR PERBEDAAN HASIL BELAJAR SISWA YANG DIAJAR MENGUNAKAN MODEL PEMBELAJARAN DISCOVERY LEARNING DENGAN PROBLEM BASED LEARNING PADA MATERI POKOK PENCEMARAN LINGKUNGAN KELAS X IPA SMA NEGERI 1 SUNGGAL
}

\author{
The Differences between Student's Learning Outcomes That Were Taught by Used Discovery Learning with \\ Problem Based Learning Models On Topic of Environmental Pollution in Grade X IPA SMA Negeri 1 Sunggal \\ Trioki Ningsih", Puji Prastowo \\ Program Studi Pendidikan Biologi, FMIPA, Universitas Negeri Medan, Jalan Wiliem Iskandar Pasar V Medan \\ Estate, Medan, Indonesia, Kode Pos 20221. E-mail: triokiningsih3@gmail.com
}

Abstrak

Penelitian ini bertujuan untuk mengetahui perbedaan hasil belajar siswa yang diajar menggunakan model pembelajaran discovery learning dan problem based learning pada materi pokok pencemaran lingkungan kelas X IPA di SMA Negeri 1 Sunggal tahun pembelajaran 2014/2015. Populasi yang digunakan dalam penelitian ini adalah seluruh siswa kelas X SMA Negeri 1 Sunggal yaitu sebanyak 4 kelas dengan jumlah siswa seluruhnya sebanyak 156 orang siswa. Sampel diambil secara acak (random sampling) sebanyak dua kelas yaitu kelas $X_{2}$ sebagai kelas yang diajar menggunakan model pembelajaran discovery learning dan kelas $X_{1}$ sebagai kelas yang diajar menggunakan model pembelajaran problem based learning yang masing-masing berjumlah 39 orang siswa, sehingga jumlah sampel dalam penelitian ini sebanyak 78 orang siswa. Jenis penelitian yang dilakukan adalah eksperimen. Hasil penelitian menunjukkan bahwa hasil belajar siswa yang diajar menggunakan model pembelajaran discovery learning adalah 82,05 $\pm 8,25$; sedangkan hasil belajar siswa yang diajar menggunakan model pembelajaran problem based learning adalah 76,41 $\pm 8,15$. Dari hasil Uji-t pada taraf $\alpha=0,05$ dengan $t_{h}$ sebesar 3,044; $t_{t}$ sebesar 1,995; dan dk 76 menunjukkan bahwa ada perbedaan yang signifikan terhadap hasil belajar siswa yang diajarkan dengan menggunakan model discovery learning dan problem based learning pada materi pencemaran lingkungan kelas X IPA di SMA Negeri 1 Sunggal tahun pembelajaran 2014/2015.

Kata kunci: discovery learning, hasil belajar, model pembelajaran, problem based learning

\section{Abstract}

This research aimed to determine the differences between student's learning outcomes that were taught by used discovery learning and problem based learning models on topic of environmental pollution in grade x SMA Negeri 1 Sunggal in academic year 2014/2015, The population of all of the students at grade $X$, that consisted of 4 classes and total of the students were 156 students. The samples were taken at random sampling of two classes, with details class $\mathrm{X}_{2}$ used discovery learning model and $\mathrm{X}_{1}$ used problem based learning model and each class numbered 39 students, so the number of samples in this study were 78 students. Type of research was experimental. The results showed that the learning outcomes of students who were taught by using discovery learning model was $82,05 \pm 8,25$, while the learning outcomes of students who were taught by using the problem based learning model was 76,41 $\pm 8,15$. The result from the t-test at $\alpha=0,05$ with $t_{h} 3,044 ; t_{t}$ 1,995; and dk 76 refer that there was significant different from student's learning outcomes who were taught using discovery learning model with problem based learning model on topic of environmental pollution in grade X SMA Negeri 1 Sunggal in academic year 2014/2015.

Keywords : discovery learning, learning model, learning outcomes, problem based learning

\section{PENDAHULUAN}

Pendidikan merupakan hal terpenting bagi semua manusia. Pendidikan menjadi bagian yang tidak dapat dipisahkan dari manusia mulai dari lahir hingga ke liang lahat. Dengan perkembangan zaman sekarang ini, pendidikan di Indonesia harus terus bergerak mengikuti perkembangan ilmu pengetahuan yang maju. Diabad 21, para siswa menghadapi berbagai risiko dan ketidakpastian sejalan dengan perkembangan lingkungan yang 
begitu pesat, seperti teknologi, ilmu pengetahuan, ekonomi, dan sosial budaya. Sehingga siswa dituntut untuk belajar lebih banyak dan proaktif agar mereka memiliki pengetahuan dan keterampilan/keahlian yang memadai.

Membahas tentang pendidikan tidak jauh dengan tolak ukur yang disebut dengan hasil belajar. Hasil belajar merupakan proses untuk menentukan nilai belajar siswa melalui kegiatan penilaian atau pengukuran hasil belajar. Tujuan utamanya adalah untuk mengetahui tingkat keberhasilan yang dicapai oleh siswa setelah mengikuti suatu kegiatan pembelajaran, tingkat keberhasilan tersebut kemudian ditandai dengan skala nilai berupa huruf, kata, atau simbol. Apabila tujuan utama kegiatan hasil belajar ini sudah terealisasi, maka hasilnya dapat difungsikan dan ditunjukkan untuk berbagai keperluan (Dimyati 2006). Djamarah (2006) lebih lanjut menegaskan bahwa hasil belajar adalah hasil yang diperoleh berupa kesan-kesan yang mengakibatkan perubahan dalam diri individu sebagai hasil dari aktivitas dalam belajar. Hamalik (2003) mengklasifikasikan hasil belajar ke dalam tiga domain (ranah) yaitu: ranah kognitif, afektif, dan psikomotor.

Kurikulum 2013 melalui pendekatan sainstifik dan kontekstual dalam pembelajaran ini diharapkan siswa memiliki kompetensi yang seimbang antara sikap, keterampilan, dan pengetahuan yang jauh lebih baik dari sebelumnya. Proses pembelajaran berpusat pada guru, dalam kurikulum 2013 diharapkan siswa juga aktif dalam proses pembelajaran. Di samping itu hasil belajarnya diharapkan melahirkan peserta didik yang produktif, kreatif, inovatif, dan afektif melalui penguatan ranah sikap, keterampilan, dan pengetahuan yang terintegrasi (Hosnan 2014).

Pada kenyataannya, proses pembelajaran yang berlangsung saat ini belum sepenuhnya berpusat pada siswa. Hal ini terlihat ketika melakukan pengamatan terhadap proses pembelajaran yang berlangsung di SMA Negeri 1 Sunggal. Menurut hasil observasi yang telah dilakukan pada tanggal 23 Januari 2015 menunjukkan bahwa siswa belum banyak terlibat dalam kegiatan pembelajaran Biologi. Karena guru belum mengajak siswa untuk mengamati fenomena-fenomena di sekitar, mengajukan pertanyaan mengenai hal yang belum dipahami, mengumpulkan infomasi, mengolah informasi, dan mengkomunikasikannya. Model cooperative learning yang dilakukan guru baru sekedar mengintruksikan siswa untuk mendiskusikan jawaban dari soal yang diberikan pada tiap kelompok. Selain itu, guru lebih aktif menjelaskan materi yang diikuti dengan pembahasan jawaban soal diskusi. Guru tidak membimbing siswa menemukan konsep yang dipelajari sehingga proses pembelajaran yang terjadi hanya satu arah.

Berdasarkan hasil wawancara dengan salah satu guru Biologi menyatakan bahwa sebagian guru telah menggunakan model cooperative learning dengan pendekatan sainstifik namun dalam pengaplikasiannya guru menjelaskan jawaban dari soal diskusi tanpa melibatkan peran aktif siswa untuk menanggapinya. Hal ini dikarenakan guru menghindari diskusi-diskusi yang terlalu luas cakupannya yang dapat memicu keributan di dalam kelas dan menyebabkan proses pembelajaran menjadi tidak kondusif dan membosankan. Dengan kata lain, pembelajaran masih bersifat satu arah. Kelemahan dari proses pembelajaran yang bersifat satu arah tersebut siswa hanya dapat menguasai materi sebatas apa yang disampaikan oleh guru, keterampilan yang dikuasai hanya sebatas lower order thinking. Jika terjadi hal seperti ini maka dapat mengakibatkan kurangnya minat siswa dan tidak semua siswa mampu aktif dalam proses belajar mengajar di kelas. Hal ini terlihat dari presentasi kriteria ketuntasan minimal yang diperoleh siswa sebanyak $60 \%$ siswa yang dapat mencapai kriteria ketuntasan minimal dan $40 \%$ siswa yang tidak mencapai kriteria ketuntasan minimal.

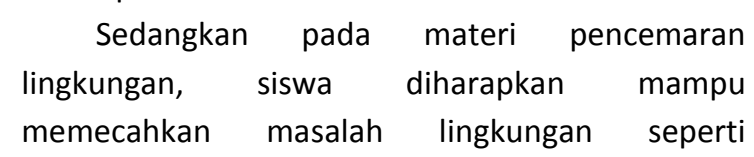
mengatasi masalah pencemaran lingkungan atau memberi solusi terhadap masalah tersebut dan menerapkan ilmu pengetahuan yang telah diperoleh dalam kegiatan belajar mengajar ke lingkungan sekitar. Untuk mengatasi masalah tersebut salah satu cara yang dapat digunakan 
adalah dengan menggunakan model pembelajaran dan dapat mengubah kegiatan belajar mengajar yang berorientasi pada guru menjadi berorientasi pada siswa (Kurinasih \& Berlin 2014). Model pembelajaran adalah seluruh rangkaian penyajian materi ajar yang meliputi segala aspek sebelum, sedang, dan sesudah pembelajaran yang dilakukan guru serta segala fasilitas yang terkait yang digunakan secara langsung atau tidak langsung dalam proses belajar mengajar (Istarani 2012). Model pembelajaran saintifik proses juga akan sangat bermanfaat bagi siswa dalam hal membina kepekaan siswa terhadap berbagai problematika yang terjadi di sekitarnya. Melalui model ini siswa akan dibiasakan untuk mengumpulkan sejumlah informasi, isu-isu penting, dan kejadian kontekstual lainnya melalui kegiatan bertanya, meneliti, dan menalar (Abidin Y 2014). Model pembelajaran mempunyai empat ciri khusus, yaitu: bersifat rasional teoritis, berorientasi pada pencapaian tujuan pembelajaran, berpijak pada cara khusus agar model tersebut sukses dilaksanakan, dan berpijak pada lingkungan belajar kondusif agar tujuan pembelajaran dapat tercapai (Suyanto 2013).

Hosnan (2014) menuliskan bahwa model discovery learning adalah suatu model pembelajaran dimana siswa didorong untuk belajar sebagian besar melalui keterlibatan aktif mereka sendiri dengan konsep-konsep, prinsip-prinsip dan guru mendorong siswa untuk memiliki pengalaman melakukan percobaan yang memungkinkan mereka menemukan prinsip-prinsip untuk diri mereka sendiri. Sedangkan model pembelajaran problem based learning merupakan salah satu alternatif pembelajaran untuk menuntun siswa belajar yang berorientasi kepada ilmu pengetahuan dan teknologi serta lingkungan sehingga mampu memecahkan permasalahan dalam kehidupan sehari-hari (Permendikbud 2013). Dengan melibatkan keaktifan siswa di kelas, pembelajaran dapat berjalan secara aktif dan siswa dapat menguasai pelajaran serta mampu mencapai kompetensi-kompetensi yang ada. Berdasarkan uraian di atas, tujuan yang diharapkan dalam penelitian adalah untuk mengetahui perbedaan hasil belajar siswa yang diajar menggunakan model pembelajaran Discovery Learning dengan Problem Based Learning pada materi pokok Pencemaran Lingkungan kelas X IPA SMA Negeri 1 Sunggal T.P 2014/2015.

\section{METODE PENELITIAN}

Populasi dalam penelitian ini adalah seluruh siswa kelas X IPA SMA Negeri 1 Sunggal Tahun Pembelajaran 2014/2015 yang berjumlah empat kelas dengan jumlah siswa 156 orang. Sampel penelitian yang diambil dua kelas yaitu kelas $X_{2}$ sebagai kelas discovery learning dan kelas $X_{1}$ sebagai kelas problem based learning. Pengambilan sampel pada penelitian ini adalah dengan cara acak (random sampling). Penelitian ini termasuk penelitian eksperimen, yaitu untuk membedakan hasil belajar siswa. Jenis penelitian ini menggunakan data kuantitatif yang merupakan nilai dari hasil belajar siswa yang diberi penskoran. Instrumen yang digunakan pada penelitian ini adalah tes hasil belajar. Instrumen tes terdiri dari 40 butir soal diujicobakan terlebih dahulu sebelum instrumen digunakan dalam penlitian, yaitu uji validitas, uji reliabilitas, taraf kesukaran soal, dan daya pembeda soal. Berdasarkan hasil uji coba tersebut diperoleh 25 soal yang layak digunakan dalam penelitian.

Teknik analisis data yang digunakan adalah analisis dengan menggunakan rumus Uji-t. Sebelum melakukan Uji-t, terlebih dahulu mentabulasi jumlah skor pre-test dan post-test, menghitung nilai rata-rata, dan menghitung varians dari kedua kelas. Setelah itu melakukan uji prasyarat data yang terdiri dari uji normalitas dan uji homogenitas. Kemudian melakukan uji-t dengan taraf signifikan $\alpha=0,05$ dan $d k=\left(n_{1}+n_{2}-\right.$ 2).

\section{HASIL PENELITIAN}

Diperoleh nilai rata-rata hasil belajar siswa pada kelas model pembelajaran discovery learning adalah $82,05 \pm 8,25$ dan varians sebesar 68,10 . Nilai tertinggi yaitu 96 dengan frekuensi $1(2,56 \%)$, nilai terendah yaitu 52 dengan frekuensi 1 (2,56\%), dan nilai dengan frekuensi tertinggi yaitu 76 dengan frekuensi 9 (23,08\%). Sedangkan nilai rata- 
Halaman : $001-006$

rata hasil belajar siswa untuk kelas model pembelajaran problem based learning adalah $76,41 \pm 8,15$ dan varians sebesar 66,35. Nilai tertinggi yaitu 92 dengan frekuensi 3 (7,69\%), nilai terendah yaitu 68 dengan frekuensi 3 (7,69\%), dan nilai dengan frekuensi tertinggi yaitu 76 dengan frekuensi 12 (30,77\%) (Tabel 1).

Tabel 1. Hasil Belajar Kelas Model Pembelajaran Discovery Learning dan Problem Based Learning

\begin{tabular}{|c|c|c|c|c|c|}
\hline \multirow[b]{2}{*}{ NO } & \multirow[b]{2}{*}{ Nilai } & \multicolumn{2}{|c|}{ Kelas Discovery Learning } & \multicolumn{2}{|c|}{ Kelas Problem Based Learning } \\
\hline & & $\begin{array}{c}\text { Frekuensi } \\
\text { Absolut }\end{array}$ & $\begin{array}{l}\text { Frekuensi } \\
\text { Relatif (\%) }\end{array}$ & Frekuensi Absolut & Frekuensi Relatif (\%) \\
\hline 1. & 96 & 1 & 2,56 & 0 & 0,00 \\
\hline 2. & 92 & 0 & 0,00 & 3 & 7,69 \\
\hline 3. & 88 & 1 & 2,56 & 2 & 5,13 \\
\hline 4. & 84 & 8 & 20,51 & 6 & 15,38 \\
\hline 5. & 80 & 7 & 17,95 & 9 & 23,08 \\
\hline 6. & 76 & 9 & 23,08 & 12 & 30,77 \\
\hline 7. & 72 & 7 & 17,95 & 4 & 10,26 \\
\hline 8. & 68 & 2 & 5,13 & 3 & 7,69 \\
\hline 9. & 64 & 2 & 5,13 & 0 & 0,00 \\
\hline 10. & 60 & 1 & 2,56 & 0 & 0,00 \\
\hline 11. & 52 & 1 & 2,56 & 0 & 0,00 \\
\hline \multicolumn{2}{|c|}{ Jumlah } & 39 & 100 & 39 & 100 \\
\hline \multicolumn{2}{|c|}{ Rata-Rata } & \multicolumn{2}{|c|}{82,05} & \multicolumn{2}{|c|}{76,41} \\
\hline \multicolumn{2}{|c|}{ SD } & \multicolumn{2}{|c|}{8,25} & \multicolumn{2}{|c|}{8,15} \\
\hline \multicolumn{2}{|c|}{ Varians } & \multicolumn{2}{|c|}{68,10} & \multicolumn{2}{|c|}{66,35} \\
\hline
\end{tabular}

Sebelum dilakukan analisis data untuk menguji hipotesis maka data yang diperoleh terlebih dahulu diuji normalitas dan homogenitasnya. Dalam hal ini pengujian normalitas data digunakan dengan menggunakan teknik Liliefors. Teknik Liliefors menggunakan pendekatan pemeriksaan individu secara keseluruhan. Dapat dilihat bahwa data pretest kelas discovery learning adalah $L_{\text {hitung }}$ 0,0915 dan post-test sebesar $L_{\text {hitung }} 0,1370$ sedangkan data pretest pada kelas problem based learning adalah $L_{\text {hitung }}$ 0,1262 dan post-test sebesar $L_{\text {hitung }} 0,1205$ dengan masing-masing $L_{\text {tabel }}$ adalah 0,142. Dimana $L_{\text {hitung }}<L_{\text {tabel }}$ sehingga semua data dapat dikatakan berdistribusi normal (Tabel 2).

Tabel 2. Data Hasil Uji Normalitas Pretest dan Post-test

\begin{tabular}{clccc}
\hline Data & \multicolumn{1}{c}{ Kelas } & $\mathbf{L}_{\text {hitung }}$ & $\mathbf{L}_{\text {tabel }}$ & Keterangan \\
\hline \multirow{2}{*}{ Pretest } & Discovery Learning & 0,0915 & 0,142 & Normal \\
& Problem Based Learning & 0,1370 & 0,142 & Normal \\
\multirow{2}{*}{ Post-test } & Discovery Learning & 0,1262 & 0,142 & Normal \\
& Problem Based Learning & 0,1205 & 0,142 & Normal \\
\hline
\end{tabular}

Pengujian homogenitas dilakukan untuk mengetahui variasi populasi bersifat homogen jika $\mathrm{F}_{\text {hitung }}<\mathrm{F}_{\text {tabel }}$ pada tabel distribusi $\mathrm{F}$ dengan taraf signifikan $\alpha=0,05$. Nilai pretest discovery learning dengan varians 72,57 dan problem based learning dengan varians 109,97 memiliki nilai $F_{\text {hitung }}$ sebesar 1,23 dan $F_{\text {tabel }}$ sebesar 1,72. Dan nilai post-test discovery learning dengan varians 68,10 dan problem based learning dengan varians 66,35 memiliki nilai $F_{\text {hitung }}$ sebesar 0,99 dan $F_{\text {tabel }}$ sebesar 
1,72. Dimana $F_{\text {hitung }}<F_{\text {tabel }}$ maka $H_{a}$ diterima (homogen). disimpulkan bahwa kedua kelas eksperimen (discovery learning dan problem based learning) adalah sama atau dengan kata lain kedua kelas sampel adalah homogen, baik pada data pretest dan post-test (Tabel 3).

Tabel 3. Data Hasil Uji Homogenitas Data Pretest dan Post-test

\begin{tabular}{clllll}
\hline Data & \multicolumn{1}{c}{ Kelas } & Varians & $\mathbf{F}_{\text {hitung }}$ & $\mathbf{F}_{\text {tabel }}$ & Keterangan \\
\hline \multirow{2}{*}{ Pretest } & Discovery Learning & 72,57 & \multirow{2}{*}{1,23} & 1,72 & Homogen \\
& Problem Based Learning & 109,97 & & & \\
Post- & Discovery Learning & 68,10 & \multirow{2}{*}{0,99} & 1,72 & Homogen \\
test & Problem Based Learning & 66,35 & & & \\
\hline
\end{tabular}

Setelah pengujian normalitas dan homogenitas data dilakukan, maka selanjutnya data hasil penelitian yang didapatkan akan digunakan dalam pengujian hipotesis yang dikenal dengan Uji-t. Uji hipotesis kesamaan 2 rata-rata (uji 2 pihak) digunakan Uji-t dengan taraf signifikan $\alpha=$ 0,05 derajat kebebasan $(\mathrm{dk})=\left(\mathrm{n}_{1}+\mathrm{n}_{2}-2\right)$. Hasil pengujian hipotesis data post-test diperoleh $t_{\text {hitung }}>$ $t_{\text {tabel }}$ yaitu $3,044>1,995$. Dari perhitungan diperoleh bahwa $t_{\text {hitung }}$ dengan nilai 3,044 pada tabel $\mathrm{dk}=76$ dengan taraf signifikan $\alpha=0,05$, karena tidak terdapat dalam daftar $t$, maka dicari distribusi $t$ dengan interpolasi linier sehingga diperoleh $t_{\text {tabel }}$ sebesar 1,995 . Sehingga $H_{a}$ diterima $\mathrm{H}_{0}$ ditolak pada taraf $\alpha=0,05$ yang berarti bahwa terdapat perbedaan hasil belajar biologi yang diajar menggunakan discovery learning dan problem based learning pada materi pencemaran lingkungan kelas X SMA Negeri 1 Sunggal tahun pembelajaran 2014/2015 (Tabel 4).

Tabel 4. Data Hasil Uji-t

\begin{tabular}{|c|c|c|c|c|c|c|c|}
\hline Data & Kelas & $\mathbf{N}$ & $x$ & SD & $t_{\text {hitung }}$ & $t_{\text {tabel }}$ & Keterangan \\
\hline \multirow{3}{*}{$\begin{array}{l}\text { Post- } \\
\text { test }\end{array}$} & Discovery & & & & & & \\
\hline & $\begin{array}{l}\text { Learning } \\
\text { Problem Based }\end{array}$ & 39 & 82,05 & 8,25 & 3,044 & 1,995 & $\mathrm{H}_{\mathrm{a}}$ Diterima \\
\hline & Learning & 39 & 76,41 & 8,15 & & & \\
\hline
\end{tabular}

\section{PEMBAHASAN}

Melihat perbedaan hasil belajar siswa pada kedua kelompok penelitian dapat diketahui bahwa nilai rata-rata discovery learning $(82,05)$ lebih tinggi dari problem based learning $(76,41)$ dan berbeda secara signifikan pada $\alpha=0,05$. Hasil belajar siswa ini menunjukkan bahwa pembelajaran dengan strategi discovery learning memudahkan siswa dalam memahami materi pencemaran lingkungan. Hal ini disebabkan karena pada model pembelajaran discovery learning dilakukan dengan cara mendorong siswa untuk memiliki pengalaman langsung dan melakukan percobaan/eksperimen sehingga mereka dapat menemukan konsep-konsep dan prinsip-prinsip untuk diri mereka sendiri. Dengan mengaplikasikan metode discovery learning secara berulang-ulang dapat meningkatkan kemampuan penemuan diri individu (siswa) yang bersangkutan. Penggunaan metode discovery learning dapat merubah kondisi belajar yang pasif menjadi aktif dan kreatif. Mengubah pembelajaran yang berpusat pada guru menjadi berpusat pada siswa. Mengubah yang dahulunya siswa hanya menerima informasi secara keseluruhan dari guru ke siswa yang dapat menemukan informasi sendiri.

$\mathrm{Hal}$ ini didukung oleh hasil peneliti Surprihatin dkk. (2014) yang menuliskan bahwa penerapan strategi pembelajaran discovery learning pada materi sistem pencernaan dapat berpengaruh terhadap hasil belajar siswa di SMA Negeri 3 Pekalongan. Hasil belajar siswa menunjukkan $\geq 98,33 \%$ siswa mengalami peningkatan hasil belajar sedang sampai tinggi. 
Discovery learning memposisikan para siswa tepat di tengah proses belajar mengajar, sehingga mereka dapat aktif mencari informasi yang dicari. Baik melalui observasi, bertukar pendapat ataupun berdiskusi, dan melakukan eksperimen untuk membuktikan teori dan kenyataan yang terjadi tentang materi pencemaran lingkungan untuk menghasilkan sebuah kesimpulan.

Sedangkan pada pembelajaran problem

based learning dilakukan dengan cara menggunakan masalah nyata sebagai sarana bagi peserta didik untuk mengembangkan pengetahuan dan kemampuan berpikir serta pemecahan masalah. Melakukan diskusi yang meliputi pengajuan pertanyaan atau masalah dan penyelidikan atas suatu masalah yang dibahas. Dan proses belajarnya dilakukan hanya sebatas diskusi kelompok dan tidak melakukan pengalaman atau eksperimen langsung.

Model discovery learning lebih tinggi dibandingkan dengan model problem based learning karena pada model discovery learning lebih menonjolkan praktikum langsung untuk menemukan akar dari suatu permasalahan. Siswa diajak untuk menemukan sendiri, menyelidiki sendiri. Sehingga hasil yang diperoleh siswa akan tahan lama dalam ingatan, tidak akan mudah dilupakan oleh siswa.

\section{SIMPULAN}

Hasil belajar siswa yang diajar menggunakan model pembelajaran discovery learning $(82,05 \pm 8,25)$ lebih baik dibandingkan dengan model pembelajaran problem based learning $(76,41 \pm 8,12)$ dan berbeda secara signifikan. Hal ini disebabkan karena model discovery learning lebih menonjolkan praktikum langsung untuk menemukan akar dari suatu permasalahan. Siswa belajar berpikir analisis dan mencoba memecahkan sendiri problem yang dihadapi dengan cara diajak untuk menemukan sendiri ataupun menyelidiki sendiri melalui observasi maupun eksperimen langsung sehingga hasil eksperimen yang siswa lakukan akan diingat terus oleh siswa.

\section{UCAPAN TERIMA KASIH}

Terima kasih penulis ucapkan kepada Kepala SMA Negeri 1 Sunggal, Deli Serdang Drs. Ramli Siregar, M.Si. dan Ibu Elvi Julianida Daulay, S.Pd, M.Si selaku guru Biologi di kelas $X_{1}$ dan $X_{2}$.

\section{DAFTAR PUSTAKA}

Abidin Y. 2014. Desain Sistem Pembelajaran Dalam Konteks Kurikulum 2013. Bandung: PT Rafika Aditama.

Dimyati. 2006. Pembelajaran Kooperatif. Surabaya: Universitas Surabaya.

Djamarah ZA. 2006. Strategi Belajar Mengajar. Jakarta: Rineka Cipta.

Hamalik. 2003. Perencanaan Pengajaran Berdasarkan Pendekatan System. Jakarta: Bumi Aksara.

Hosnan. 2014. Pendekatan Saintifik Dan Kontekstual Dalam Pembelajaran Abad 21, Kunci Sukses Implementasi Kurikulum 2013. Bogor: Ghalia Indonesia.

Istarani. 2011. Model-model Pembelajaran. Bandung: Grafindo.

Kurinasih I, Berlin. 2014. Sukses Mengimplementasikan Kurikulum 2013, Memahami Berbagai Aspek Dalam Kurikulum 2013. Surabaya: Penerbit Kata Pena.

Permendikbud. 2013. Lampiran Peraturan Menteri Pendidikan dan Kebudayaan Republik Indonesia No. 81a Tahun 2013. Jakarta: Menteri Pendidikan dan Kebudayaan Republik Indonesia.

Suprihatin, Wiwi I, Wulan C. 2014. Aktivitas dan Hasil Belajar Siswa pada Materi Sistem Pencernaan dengan Penerapan Strategi Pembelajaran Discovery Learning. Unnes Journal of Biologi Education. 3(3)(2014). ISSN 2252-6579. [diakses 12 Februari 2015]. Tersedia pada http://journal.unnes.ac.id/sju/index.php Lujbe/article/viewFile/4526/4176

Suyanto, Asep J. 2013. Menjadi Guru Profesional. Jakarta: Penerbit Esensi Erlangga Group. 